\title{
Liberdade e valor $(*)$
}

\section{Miguel Reale}

Catedrático de Filosofia do Direito na Faculdade de Direito da Universidade de São Paulo.

\section{O problema no fim do século passado}

1 - Em um pequeno ensáio intitulado "Normas e leis naturais", inserto na sua obra Präludien, Wilhelm Windelband apresenta-nos talvez o ponto extremo a que chegara a problemática filosófica, no fim do século passado, no que tange ao tema Liberdade e valor.

Ponto de partida do mencionado trabalho é a afirmação de que não seria possivel tratar de preceitos e de sua vigência se não existisse no homem uma potência capaz de dar um salto por cima das funções naturalmente necessárias da vida psíquica, se não existisse, em suma, a liberdade.

O problema da liberdade, dêsse modo, é posto exclusivamente em função de uma dupla lei que regeria tôda a experiência humana: de um lado, a lei determinista própria do mundo da natureza; do outro, a lei do dever moral própria do mundo "noumênico".

O problema ético da liberdade ainda é posto, como se vê, com base na distinção essencial entre leis naturais e

(*) Trabalho escrito a convite da Comissão Organizadora do XII Congresso Internacional de Filosofia, realizado em Veneza, em setembro do corrente ano. Os demais relatores gerais do referido certame foram os professôres Aloys DempF, de Munique: PHILIPP Frank, de Cambridge; Johann Lotz de Pullach, de Munique; M. B. Mitin, de Moscou; Richard Mackeon, de Chicago; Adolfo Muñoz Alônso, de Valência; Alfred Jules Aerr, de Londres; Chaim PerelMAN, de Bruxelas; e AIMÉ Forest, de Montpellier. 
leis normativas, atendidas as exigências então dominantes na cultura ocidental, ou seja, sem quebra da crença inabalável no princípio de causalidade, concebido de maneira absoluta e determinista, como condição universal de tôdas as ciências.

Se as leis naturais ou leis explicativas dos fenômenos, segundo a categoria lógica do ser, não coincidem com as leis do dever ser ou normas, nem por isto se admite uma contradição entre elas: as normas, em última análise, representam uma seleção operada no complexo de possibilidades das leis naturais. Neste sentido, uma regra de qualquer natureza, - seja ela moral, lógica ou estética, - pode converter-se em fundamento determinante do pensamento e da vontade, desde o momento em que se insere no plano da consciência.

"Sòmente assim, conclui Windelband, poderemos compreender a atualização das normas no processo naturalmente necessário da vida psíquica do homem, sem se anular a condicionalidade causal de tôdas as suas distintas funções."

Daí o seu conceito de liberdade como sendo "a determinação da consciência empírica mediante a consciência normativa", ou o domínio do homem sôbre a sua consciência segundo uma lei, cujo valor é por êle mesmo expontâneamente reconhecido. Ser livre significa obedecer à razão, entendida como o conjunto dos valores e das normas, de maneira que, tudo somado, julga-se possível resolver o problema da liberdade tão sòmente à luz dêstes dois princípios complementares: a vigência normativa ou axiológica da consciência, em harmonia com o enlace teorético da causalidade natural.

\section{Recolocação radical do problema}

2 - Não resta dúvida que a tese, ora recordada a título de exemplo, e que, no fundo representa uma reela- 
boração de distinções fundamentais da filosofia kantiana, baseia-se sôbre um sistema de pressupostos, ou se quiserem, de perspectivas, que foram depois alvo de penetrantes análises, reveladoras de trincas e lacunas, das quais devia resultar grande parte da problemática filosófica contemporânea.

Se fôsse possível proceder-se, no breve espaço concedido a esta comunicação, a uma pesquiza completa sôbre os motivos profundos que tornaram inatuais certas "conquistas definitivas" com que se engalanaram a ciência e a filosofia no século passado, não obstante se proclamasse o caráter problemático do saber filosófico, talvez compreenderíamos melhor a razão pela qual o problema liberdade-valor, enquanto diade inscindível, passou, em nossa época, por uma alteração radical. Tão radical que atinge e envolve tôda a concepção do homem, não do homem como pura abstração racional, mas na concretitude de seu ser existencial e histórico.

Como observa Nicola Abbagnano, "não se trata mais de um contraste entre as afirmações da ciência, implicando no determinismo rigoroso de todos os eventos da natureza e, por conseguinte, também da vontade humana, e as exigências da vida moral. Esta formulação do problema da liberdade, tal como foi proposta pela filosofia da última centúria, pode ser considerada completamente inatual. O conflito que dá origem ao problema não é mais o afirmado entre duas disciplinas ou entre dois pontos de vista, segundo os quais possa ser considerada a vida do homem como sendo de um lado natureza, e, do outro, espírito. Trata-se de um conflito mais profundo, radicado na essência mesma do homem e nas suas atitudes concretas" (1).

3 - E claro que mesmo no século passado é possível encontrar as raizes da problemática axiologia hodierna. Os nomes de Kierkegaard e de Nietzsche bastariam para

(1) Abbagnano - Introduzione all'esistenzialismo, 1947, pág. 107. 
demonstrar que nem sempre se poz o problema da liberdade do homem de um modo, por assim dizer, extrínseco ao homem mesmo, porque referido ao mundo da natureza, concebida como um sistema fechado de fatos e de cousas.

Soren Kierkegaard, com efeito, não concebe a liberdade em função ou em contraste com um rígido sistema de fôrças naturais, nem a priva de tôda singularidade pessoal, projetando-a como categoria abstrata no plano "noumenal", mas, ao contrário, a reconduz ao valor intrínseco da subjetividade: em certo sentido, é da sua condição de "ser no mundo" que o homem extrai a possibilidade de transcender o mundo.

Nietzsche, por sua vez, é só aparentemente que se serve dos pressupostos da biologia evolucionista para modelar o homem ideal, porque infinitamente real, o "super homem" que vai progressivamente se criando a si mesmo como livre produto de seus próprios meios. A liberdade, entendida como expontaneidade criadora, identifica-se com o valor radical do homem; e o homem, que procura se libertar da história, haure na história as fôrças indispensáveis ao seu incessante superamento.

Eis aí, a meu ver, duas antecipações do tema liberdade-valor como núcleo central de uma antropologia filosófica, tal como hoje se nos antolha, em conexão com novas formas de entendimento dos problemas da existência, da possibilidade e da transcendência.

$\mathrm{Na}$ linha de pensamento do filósofo dinamarquês o $e u$ reencontra a si mesmo diante de Deus, e sòmente se reconhece livre na inefável singularidade de sua relação com o Outro: a liberdade é posta, portanto, como valor conatural à consciência da finitude e da precariedade do homem, em uma transcendência absoluta.

No pensamento de Nietzsche, ao contrário, desloca-se o conceito de interioridade, do eu para a natureza, a qual se anima tôda em virtude da projeção do homem, fonte de sentido e valor: a liberdade é transcendência do homem 
como auto-criação imprevisivel, através das infinitas formas da experiência humana.

Nạs duas direções, porém, - não obstante a contraposição dos respectivos conceitos de homem e de transcendência, - o que se torna manifesto é a acentuada preocupação pelas raízes do ser humano, pela liberdade e pelo valor como condições de superamento da condicionalidade existencial.

\section{Da ética à ontologia da liberdade}

4. - Se tivesse de escolher um ponto de referência para tentar a difícil esquematização das diversas tendências ou perspectivas reveladas na axiologia contemporânea, no que concerne à implicação liberdade--valor, elegeria o ligado ao problema da transcendência. É êste, com efeito, um motivo dominante nas investigações atuais sôbre a matéria, apesar da multiplicidade de suas diretrizes, muitas vêzes entrecruzadas e sobrepostas, mesmo porque tem suscitado no campo adverso o reexame de teses fundamentais, como ocorre nas concepções, por exemplo, do idealismo imanentista ou nas diversas formas de naturalismo. Cabendo-me, no entanto, a tarefa de proceder a um levantamento da situação atual do problema, sem a preocupação de traçar as fronteiras das doutrinas, aliás frequentemente imprecisas ou cambiantes, julgo preferível focalizar a correlação liberdade-valor à luz de vários prismas.

Sem esquecer o que deve ter resultado, para o nosso tema, da crítica dos pressupostos do saber científico, desde quando se poz em dúvida a fé no determinismo universal, - e abstração feita, por ora, das diversas doutrinas filosóficas que puzeram em realce a contigência das leis naturais, talvez seja possível afirmar que a mudança fundamental operada neste assunto, nos últimos decênios, 
consistiu na transladação do problema da liberdade, do plano ético para o plano ontológico.

Basta lembrar que grande parte da problemática axiológica contemporânea se relaciona com a crítica de três teses nucleares do criticismo transcendental: a distinção, para não dizer a separação entre liberdade e temporalidade; a distinção entre ser e dever ser; e, finalmente, a postulação da liberdade como "noumeno", isto é, como autoconsciência do puro dever.

Já foi justamente observado que no sistema de Kant o valor se separa do ser, enquanto que ainda para os cartesianos um ser tanto mais vale quanto mais é. Liberdade e valor, na doutrina do filósofo germânico, passam a ser pensados como um mundo "a se", o mundo da liberdade pura, que não pode ser objeto de "experiência", ou seja, de conhecimento teorético, mas tão sòmente de intuição prática.

Ora, a crítica de Henri Bergson desenvolve-se exatamente contra a concepção kantiana do tempo, visto como o autor da Crítica da razão pura havia confinado a liberdade no mundo da "coisa em si", excluindo-a do mundo dos fenômenos. Para Bergson, ao contrário, uma liberdade não temporal reduz-se a simples aparência de liberdade. Esta é inconcebível fora da profunda realidade do tempo, da "durée pure", assim como com abstração do "eu profundo", expressão do tempo concreto.

Desta formulação do problema resultava a necessidade de novas indagações sôbre a implicação liberdade-temporalidade-valor: o novo conceito de temporalidade como projeção do futuro sôbre o passado, - livre, portanto, de um passado que, de um ponto de vista naturalístico, já conteria em si todo o devir, - revelava, de um lado, a insuficiência e o equívoco do determinismo, e, do outro devia, a pouco e pouco, levar à consideração do valor da liberdade como temporalidade e, assim sendo, à sua inclusão ontológica na esfera dos valores. 
É na linha dêsse pensamento que se apresenta, por exemplo, a liberdade na "Philosophie de l'Ésprit", segundo a conhecida sintese de Louis Lavelle: "A função da liberdade consiste em produzir o tempo como condição de seu exercício, afim de introduzir a possibilidade no mundo como o veículo do valor" (2).

5 - Sob um prisma diferente, mas com similitude de desenvolvimento, delineia-se a descrição fenomenológica do tempo, desde Husserl até Heidegger e Jaspers, de Sartre a Merleau-Ponty, com a afirmação de que a subjetividade é temporalidade, em virtude da qual tornar-se-iam possíveis, sem contradição, "ipseidade, sentido e razão". Veremos oportunamente quais as conseqüências que podem defluir desta concepção, no que se refere ao nosso tema, sobretudo pela redução ontológica do valor à liberdade.

6 - A crítica da outra tese kantiana, ou seja, da liberdade entendida como postulação do dever, deu lugar a conseqüências igualmente relevantes para uma nova compreensão do problema.

Não é por acaso que as reservas opostas por Max Scheler ou por Nicolai Hartmann ao formalismo ético de Kant culminam em uma fenomenologia dos valores, abrindo caminho para o exame da liberdade como problema ontológico, fato êste que não pode ser interpretado precipitadamente como retôrno à ética e à metafísica tradicionais.

Enquanto que para Kant a consciência do dever, como pura lei formal, precede ao valor, na filosofia scheleriana é o valor que surge como pressuposto do dever ser: "todo dever ser, consoante afirmação incisiva de Scheler, funda-se sôbre um valor" (3).

(2) L. LAvelLE - Traité des valeurs, 1951, t. I., pág. 418.

(3) MAX SCHELER - Der Formalismus in der Ethik u. die materiale Wertethik, 1916, pág. 79. 
Esta redução do dever ao valor, ou seja, o superamento do conceito abstrato de dever e de "boa vontade", concebida como simples ponto matemático evanescente em pura virtualidade formal, implica em uma nova concepção da liberdade, ou por outras palavras, sugere uma série de novas perguntas. Por necessidade de síntese, poder-se-ia talvez dizer que os problemas se concentram na seguinte perquirição fundamental: "A obrigatoriedade e a liberdade são inerentes à essência mesma do valor como tal, isto é, ao seu modus essendi?" (4).

7 - Por mais diversas que se revelem, por conseguinte, as vias seguidas pelas correntes de pensamento ora lembradas, parece-me incontestável que nos defrontamos com uma deslocação do problema, do plano da ética para o da ontologia fundamental, ou, mais precisamente, para o de uma ontologia dos valores.

Se a liberdade está numa relação original com o valor, - tal como o próprio Kant conseguiu demonstrar, pondo sob nova luz os dados tradicionais do problema ético, e se, no entanto, a unidade kantiana entre valor e liberdade se considera realizada com prejuízo da singularidade concreta do homem, percebe-se a razão pela qual a díade liberdade-valor se converte, aos olhos dos filósofos de nossa época, no ponto nevrálgico de uma antropologia fundamental, suscitando inquietantes perguntas, como estas: A liberdade reduz-se ao valor? Ou é êste que se reduz àquela? Não estaremos, ao contrário, diante de dois têrmos que se exigem recìprocamente em uma relação de polaridade? E o que passo a analisar.

\section{Liberdade, valor e temporalidade}

8 - Max Scheler e, em parte, também Nicolai Hartmann mantêm-se ainda fiéis à tese kantiana de um dever

(4) N. Hartmann - Ethik, 1916, pág. 154 e segs. 
ser integralmente independente de tôda e qualquer referência áo futuro (os valores, segundo Scheler, por exemplo, são em si mesmos indiferentes ao ser e ao dever ser), enquanto que outros pensadores contemporâneos já sentem a necessidade de superar o dualismo dominante no ontologismo axiológico, desenvolvendo uma pesquiza aprofundada em tôrno das categorias de "possibilidade" e "temporalidade", no sentido de determinar o que, nas manifestações concretas da existência humana, poderá representar a liberdade perante um mundo de valores ideais fundantes do dever ser.

Em linhas gerais, em suma, a filosofia atual comunga nas críticas movidas contra o formalismo ético de Kant, e, diga-se de passagem, não há crítica ao formalismo kantiano que não acabe por repropor, de uma forma ou de outra, alguns problemas já formulados por Hegel e pelos néo-hegelianos. Porém, se se reconhece a precariedade de uma solução, como a de Kant, que, no fundo, priva o homem de sua singularidade pessoal para projetá-lo como homem universal, livre apenas como momento de uma coincidência abstrata e vazia com os demais homens, não é menor a repulsa à doutrina da liberdade nos moldes de Hegel, a qual, para ser concreta, se reduz a um momento do espírito absoluto.

É entre êsses dois extremos, é entre a unidade abstrata de Kant e a absolutamente concreta de Hegel que os pensadores de nossos dias procuram se situar, muitas vêzes contestando que "já agora seja imprescindível compreender a realidade reduzindo o multíplice ao uno", como sustenta, por exemplo, Ugo Spirito, apesar de seu "problematicismo." (5)

A concepção dos valores como seres ideais ou modelos eternos, nos quais o homem limitar-se-ia a espelhar-se, na sua trágica experiência vital, as distinções subtis e intelectualizantes sôbre a projeção do valor de maneira gra-

(5) Ugo SpIRIto - Significato del nostro tempo, 1955, pág. 126. 
dual e esquemática, desde o plano do dever ser puro até ao da realidade social e histórica (pense-se, por exemplo, nas discriminações de Hartmann quanto ao dever ser ideal distinto do dever ser atual, por sua vez sem conexão direta com o dever fazer algo), o dualismo entre valor e existência, julgo eu, não pode satisfazer a uma humanidade às voltas com a concretitude da ação, quando um minuto pode ter um valor infinito para o destino de cada um e de todos. Não escapou, outrossim, a pergunta sôbre a possibilidade de fundar-se uma ética da liberdade, quando se proclama a passividade do ser humano perante modelos transcendentes, ou, então, sôbre o valor de uma liberdade que se resolve em uma atitude puramente emocional, incapaz de elevar-se e de revelar-se como momento de racionalidade.

9 - Como primeiro e magnífico exemplo no sentido de compor-se em harmonia e multíplice e o uno, o existente e o transcendente, pode-se lembrar o pensamento daqueles autores que, como Lavelle, compreendem a liberdade como "uma dialética do relativo e do absoluto, que é geradora do tempo, que nos mostra que o valor é a-temporal, apesar de sujeito a descer no tempo": a liberdade é, assim, uma trajetória entre o real e o valor, interpondo-se, entre êstes têrmos, a categoria do possível (6).

À posição acima lembrada liga-se um conceito ontológico de transcendência que não significa "ir além do pensamento e da subjetividade"; que não equivale, em suma, à temporalidade como indeterminação absoluta, mas quer dizer: "ir além do tempo." A liberdade se põe como valor de participação ao Valor que nos transcende.

10 - Se a liberdade, para Le Senne, é a revelaçâo do valor (7) bem outra a concepção daqueles que situam a liberdade como "fundamento dos fundamentos", consoan-

(6) Lavelle - op. cit., pág. 418.

(7) Renk̀ LE Senne, Obstacle et valeur, s. d., pág. 211. 
te afirmação radical de Heidegger, a cujos olhos ela é o poder que o homem tem de constituir-se como "ipseidade". No ato constitutivo da transcendência, o Dasein põe-se a si mesmo e ao mundo como "ipseidade", de maneira que, em certo sentido, vêm a coincidir transcendência e liberdade. Daí a conclusão de que esta não é mais do que isto: "ir além do mundo": "Der Ueberstieg zur Welt ist die Freiheit selbst" (8).

É análoga a posição de Sartre, para quem a liberdade é o fundamento de todos os valores: o homem é um ser que não pode não ser livre. No existencialismo de Heidegger ou de Sartre não se pode, a rigor, cuidar de uma "teoria dos valores" a não ser como projeção ou derivação de uma "teoria da liberdade." "La valeur, escreve Sartre, hante l'être en tant qu'il se fonde, non en tant qu'il est: elle hante la libertè" (9).

A redução radical do valor à liberdade humana pode ser, assim, considerada uma nota prevalecente em tôdas as modalidades de filosofia existencial, excepção feita para as de orientação cristã, para as quais a liberdade nos reconduz a Deus, cuja afirmação é a afirmação de uma liberdade absoluta, pois, como declara Gabriel Marcel, "uma liberdade não pode ser afirmada senão por uma liberdade." $O$ ato pelo qual eu penso a liberdade é o ato mesmo pelo qual a liberdade se constitui, c a relação da minha liberdade com a liberdade divina representa "o mistério central da religião cristã" (10).

A radicalidade da liberdade humana, como se revela nas obras de Karl Jaspers, Ortega y Gasset, Nicola Abbagnano ou Marleau Ponty, bem como nas de Heidegger e de Sartre, apesar de sua aparência de categoria absoluta, reduz-se no entanto, à simples consciência axiológica de uma

(8) Martin Heidegger, Von Wesen des Grundes, 1931.

(9) J. P. SARTRE — L'être et le néant, 1943, pág. 137.

(10) G. MARCEL - Journal métaphysique, 1935, págs. 32, 38, 45 e passim. 
necessidade, à inexorável necessidade de sermos nós mesmos: "A nossa vontade, escreve, por exemplo, Ortega y Gasset, é livre para realizar ou não êste projeto vital que definitivamente nós somos, porém nada poderá alterá-lo, corrigi-lo, substituí-lo ou dêle prescindir. Somos indelèvelmente êste único personagem programático que não pode deixar de se realizar" (11).

Convertido o valor em liberdade, e esta em raiz primordial do ser, eis-nos perante outra forma de transcendência: "a liberdade é possível, afirma Karl Jaspers, sòmente com a transcendência e por meio dela." A transcendência é, porém, concebida como um salto "da compreensividade infinita que nós somos enquanto ser determinado (consciência, espírito), para a compreensividade infinita que podemos ser ou já somos como existência. Êste salto assinala, ao mesmo tempo, a passagem da compreensividade infinita, que reconhecemos como mundo, para a compreensividade infinita que é o ser em si mesmo" (12).

\section{Liberdade e valor na história}

11 - O valor primordial atribuído ao futuro na concepção do tempo, - ponto sôbre o qual coincidem pensadores das tendências mais diversas, de Bergson a Lavelle, de Heidegger a Dewey - implica em novos conceitos da liberdade e do valor no plano da história.

A primeira observação a ser feita é a de que temporalidade não equivale a historicidade. Esta é a temporalidade racionalmente realizada, ou, como me parece mais plausível, é a temporalidade em uma tensão racional, na

(11) Ortega y Gasset - Obras completas, pág. 1399.

(12) K. JASPERS - Filosofia dell'esistenza, trad. de A. BANFI, 1943, pág. 49. 
qual liberdade e valor se implicam e se exigem reciprocamente.

No mundo atormentado de nossos dias, que sente cada vez mais o valor do irracional e do problemático, assim como os momentos positivos e negativos da possibilidade, parece prevalecer a convicção de que a história não pode ser entendida como puro processo ideal, no qual realidade e valor se confundam, de conformidade com o princípio hegeliano da identidade do racional com o real, do ser com o dever ser, em um processo unitário e livre de quaisquer resíduos.

O reconhecimento de inevitáveis residuos irracionais na vida espiritual, que o idealismo pretendera ilusòriamente dissolver na concretitude e na imanência do ato espiritual, - passa a inspirar novas formas de "historicismo" em conexão essencial com o tema dêste trabalho. Creio mesmo que é êste um ponto crítico ou crucial da axiologia contemporânea, preocupada em superar o dualismo entre o mundo dos valores e o mundo do ser, dualismo paradoxalmente estabelecido por aquêles mesmos que sentiram e demonstraram a necessidade de uma ética material de valores, e cujo superamento nos poderá livrar da solução, não menos paralizante, proposta pelo existencialismo.

Com efeito, de um lado, no idealismo imanentista, corre-se o risco de se imobilizarem a liberdade e a história no ato espiritual, o qual, enquanto "causa sui", aparece como sendo o valor absoluto e a absoluta liberdade, fechando-se, dêsse modo, definitivamente, o processo do espírito; de outro lado, como ocorre no existencialismo, não obstante as contestações repetidas por seus mentores, não há pròpriamente lugar para a história, visto como não se vai além da mera temporalidade, ou, relevem-nos o têrmo, da "futurização" infinita.

Se no historicismo, idealista ou naturalista, o homem é o personagem de uma liberdade, ideal ou social, que se 
desenvolve objetiva e universalmente, segundo leis racionais imanentes na história, os existencialistas nos mostram o homem participando do devir histórico tão sòmente na medida e enquanto êle se revela "medium" ou veículo de uma liberdade que se nega a si mesma em cada ato de determinação; que o condena, no fundo, a aceitar conscientemente a sua inevitável situação precária de ente livre perdido na absoluta indeterminação.

12 - É a consciência bem viva das mencionadas aporias que confere certa feição singular e original a algumas expressões recentes do idealismo e do espiritualismo cristão, tanto na Europa como na América. Nota-se em alguns autores o propósito de pensar a liberdade e o valor em um ato que condicione a história, mas assegure o seu ulterior desenvolvimento, mediante uma síntese de racional e irracional. Daí resulta, diga-se de passagem, uma significativa mudança no que se possa ou se deva considerar vivo ou morto no pensamento de Hegel, procurando-se retrospectivamente nos estudos juvenis do filósofo germânico a via julgada mais em harmonia com as exigências prementes de nosso tempo.

Colhendo motivos de inspiração no idealismo de Croce, e sobretudo no de Gentile, com expressivas remissões ao ontologismo de Rosmini, os chamados "espiritualistas cristãos", na Itália, como Carlini, Stefanini, Battaglia e Sciacca, desenvolvem, por exemplo, uma axiologia que oferece muitos pontos de contacto com a de Blondel, de Lavelle e de Le Senne, mas denota um sentido mais vivo de historicidade, oriundo do já lembrado propósito de superar a redução do valor ao ato, dando a êste têrmo um significado próprio, "enquanto passagem da possibilidade à realidade e, ao mesmo tempo, abertura da realidade para novas possibilidades" (13).

(13) Felice Battaglia - I valori fra la metafisica e la storia. $1957,88$. 
Nos últimos escritos de Benedetto Croce, "estimulados por novas experiências vitais", como êle mesmo o reconhece, já afloram certas dúvidas quanto à racionalidade plena e unitária da história, mas é nas especulações do idealismo mais recente que se acentua a preocupação pelo problema do "valor da liberdade" segundo uma concepção menos otimista do homem, visto e reconhecido como centro de contradições insuperáveis.

Lembre-se, nessa ordem de idéias, que o atualismo de Gentile foi objeto de uma reelaboração hipercrítica por parte de Ugo Spirito, cujo "problematicismo" culmina na afirmação deveras surpreendente, dadas as fontes originárias de seu pensamento, de que o homem não ama a liberdade, mas sim o absoluto, e que "é a falta de certeza do absoluto que dá origem à instância da liberdade" (14). Tal conclusão bem poderia ser comparada com a de Kierkegaard: a liberdade não nasce da certeza, mas da incerteza teorética do valor absoluto.

13 - No âmbito mesmo do idealismo já fôra sentida, aliás, a importância do residual ou do irracional na problemática da liberdade, mas como momento dialèticamente superado na concretitude da vida ética. Benedetto Croce, por exemplo, reconhece que "na liberdade há o momento da não-liberdade", tendo, porém, o cuidado de esclarecer incontinenti: "o oposto ou o contrário da liberdade, o momento da contradição no processo volitivo, forma um todo único com o mesmo processo." Donde a conclusão de que "a liberdade é um nexo indissolúvel de necessidade e de liberdade" (15).

Ora, é exatamente a possibilidade dêsse superamento unitàriamente englobante que não é admitida pela maioria dos pensadores atuais, não se devendo, além do mais, olvidar, no caso especial de Croce, a estranhável carência de uma análise mais aprofundada do conceito de valor, por

(14) Ugo SpIRito - Significato del nostro tempo, cit. pág. 151.

(15) B. Croce - Filosofia della pratica, 1932, pág. 125. 
parte de um filósofo que, com inegável acuidade, desenvolvera uma concepção fundamental sôbre a circularidade do espírito baseando-se na distinção de quatro graus da vida espiritual, todos de natureza axiológica, o belo, o verdadeiro, o útil e o bem.

A fenomenologia dos valores convence-nos, em verdade, da impossibilidade da referida identificação absoluta entre valor e liberdade no âmbito do processo espiritual, visto como o valor não só implica sempre no seu contrário, como transcende cada experiência axiológica particular, cada ato que livremente se constitua: a polaridade "liberdade-valor" representa, no meu entender, a vida mesma do espírito, sendo a condição de seu "processus".

Liberdade e valor, ser e dever ser são como que fôrças que se sustentam reciprocamente em um processo de implicação e de polaridade. "Tôda atualidade é essencialmente bipolar", assevera Whitehead, ao mesmo tempo que Émile Bréhier julga poder estender a polaridade a todo o real: "A realidade é essencialmente polaridade de têrmos que se regem um ao outro" (16)

Sòmente uma dialética da implicação e da polaridade poderá explicar-nos como é que o valor não se anula quando se insere no plano do ser, por meio da liberdade, a qual é possibilidade infinita de experiências axiológicas, isto é, de ações e, por conseguinte, também um valor. Recorrendo a uma imagem feliz de Croce, diria que a liberdade está para o valor como a lógica está para a filosofia; compreende o valor superando-o, e supera-o compreendendo-o, assim como "o espelho d'água, que reflete a paisagem, é ao mesmo tempo parte da paisagem" (17).

(16) A. N. Whitehead - Process and Reality, 1929, pág. 151, e BRÉHIER - Les thèmes actuels de la philosophie, 1954, pág. 46. Sôbre a aplicação da polaridade na axiologia jurídica vide a minha Filosofia do Direito, São Paulo, 1957, 2. ${ }^{a}$ ed.

(17) B. CROCE - Logica come scienza del concetto puro, 1928, pág. 170 . 
Por outro lado, cada experiência particular de valores não está em função da liberdade exclusiva de um sujeito isolado, dependendo, ao contrário, necessàriamente, de sua intersubjetividade, pois, sendo um valor, a liberdade não pode deixar de possuir, como sua qualidade essencial, liames de solidariedade ou de copartecipação com todos os demais valores. Não é livre quem comanda escravos, nem há liberdade onde se estiolaram tôdas as virtudes. A validade da liberdade singular transcende o ato que a constitui. Daí poder-se dizer que o espírito, como sintese de liberdade e valor, é enquanto se transcende.

\section{Praxis, liberdade e valor}

14 - O novo conceito de natureza e das ciências naturais e matemáticas não podia deixar de levar o naturalismo a proceder à revisão de suas antigas teses sôbre o problema do homem, e, por conseguinte, da liberdade e do valor, como ocorre, v. g., na obra de John Dewey.

Também para o filósofo americano o futuro é a dimensão temporal básica, mas entendida como possibilidade de ação: "Um empirismo que se contente com a repetição dos fatos passados, não encontra lugar para a possibilidade e a liberdade" (18). O registro das experiências passadas fornece-nos os meios para organizar as observações e as experiências futuras. Mediante os sỉmbolos das ciências, o homem, de certa forma, antecipa o futuro e afirma-se positivamente, apesar das adversidades que o possam assaltar, não perante a natureza, mas inserido nela, por ser parte, ou melhor, agente inseparável da natureza mesma.

Possibilidade, portanto, no pragmatismo instrumentalista de Dewey, significa potencialidade, distinguindo-se o espírito pela sua capacidade de fixar-se em algo, de sair,

(18) J. DeWeY - Philosophy and Civilization, 1937, pág. 24. 
não sem lutas e sem obstáculo, do estado de incerteza para o de determinação, quer no momento teorético da pesquisa, quer no da prática. Não se trata, contudo, de possibilidade de atualização em termos de "vontade de potência", mas realística e pròpriamente, de poder de agir com eficiência.

Em um mundo assim concebido, o futuro não vem ao nosso encontro como um bem ou um mal imprevisível e gratuito da natureza, nem pode ser o resultado de uma previsão infalível e segura: é antes um desafio, um estímulo à praxis, à liberdade como condiçâo que permite ao homem empenhar-se em operações de pesquiza contrasteada. Na axiologia de John Dewey, inseparável de sua concepção da natureza, os valores equivalem a fins naturais, os quais, intrinsecamente, não são nem bons nem maus, mas valem como diretrizes em um sistema funcional e móvel de energias, de maneira que a sua relação com a liberdade se concretiza como praxis, segundo, repito, a categoria fundamental da possibilidade. Sòmente assim o homem, "individualidade qualitativa do mundo" (19), participando da interação das fôrças naturais e sociais, consegue abrir caminho para o mundo dos valores através do mundo da natureza. Consegue tal objetivo fundado em uma liberdade que, como escolha inteligente e adaptação feliz, implica na eficiência dos meios idôneos, o que só se torna possivel graças ao conhecimento dos fatos. Valor, liberdade, potencialidade e eficiência, eis os fatôres que, na doutrina de Dewey, se compõem e se congregam numa unidade indissolúvel, em unísono com o incessante progresso de nossa capacidade intelectual.

Tal conceito dinâmico de liberdade em têrmos de potencialidade parece-me constituir característica prevalecente na axiologia anglo-saxônia, manifestando-se também fora da órbita do naturalismo. Bastará lembrar aqui a

(19) J. Dewey - Experience and Nature, 1925, cap. X, e Human. Nature and Conduct, pág. 302 e segs. 
teoria de A. N. Whitehead sôbre os valores como "potencialidades ideais". Não é sem fortes motivos que Cornelius Krusé proclama a necessidade de uma "metafísica da potencialidade", não "como simples possibilidade, mas como genuina alternativa" (20).

16 - O tema essencial da liberdade como determinação no plano da praxis desenvolve-se igualmente no âmbito do materialismo dialético. Henri Lefebvre observa, significativamente, que necessidade de tomar posição ou partido, com relação a qualquer problema, "é uma exigência constante da praxis e também do pensamento, que o marxismo eleva ao nível de conceito e de princípio" (21).

Se, porém, a liberdade vale como condição para o homem se engajar na sociedade e no mundo, a dificuldade surge tão logo se afirma estar imanente no processo histórico o advento de um resultado inexorável, como seria o da sociedade comunista. Nesta hipótese, não subsiste senão a consciência de uma evolução necessária, reduzindo-se a liberdade a um potenciamento de energias destinado a remover os obstáculos contrapostos à meta idealizada. Mais do que em liberdade dever-se-ia falar em libertação, na consciência da precariedade de um status social capaz de justificar e fortalecer a ação revolucionária no processar-se da história.

Parece-me incontestável que o materialismo dialético, até e enquanto se mantém na posição ora exposta, conserva, no fundo, o seu caráter de ideologia ancorada no século XIX, fiel a uma concepção da história que porfia em modelar o futuro em função do passado, segundo as categorias de um naturalismo determinista.

(20) C. KRUSE - Man's paramount need of an adequate theory of values, in "Anais do Congresso Int. de Filosofia" de São Paulo, 1954, t. II, pág. 419.

(21) H. LeFebvre - Le matérialisme dialectique, na "Encyclopedie Française”, t. XIX - Philosophie et Religion. 
16 - Todavia, alguns pensadores de formação marxista, mais atentos à problemática filosófica de nossa época, têm procurado descobrir no marxismo elementos e motivos para um novo tipo de humanismo e para uma nova compreensão da liberdade.

Surgem, dêsse modo, novas concepções que, embora inspiradas em Karl Marx, repropõem algumas das teses fundamentais que estou procurando fixar nos amplos horizontes do pensamento contemporâneo.

À luz de nosso tema, lembraria, por exemplo, a tentativa de partir do mundo dos valores, ou melhor, da "criação incessante dos valores" para caracterizar a liberdade, que vai paulatinamente se concretizando em ações e em obras, graças ao trabalho que transforma a natureza, distinguindo-se, dessarte, da liberdade escatológica e absoluta de uma sociedade sem classes.

O valor é, nêste caso, concebido como "ação em potência", ou, por outras palavras, é visto "na perspectiva da ação." Longe de ser visualização do transcendente, o próprio valor é "transcendência in acto", criação concomitante (concriação) intersubjetiva de bens e de obras. Dada a impossibilidade de qualquer conhecimento teórico ou racional dos valores, só nos restaria trilhar o caminho de uma ética da liberdade prática, a qual não se propõe o absoluto ou o eterno, mas apenas o relativo e o temporal (22).

17: - Uma impostação diversa e mais profunda do problema da liberdade e do valor é-nos propiciada por Merleau-Ponty, em cuja teoria a fonte de todo valor é ainda a liberdade, porém em conexão necessária com a intersubjetividade, visto conıo cada homem deve ser, ao mesmo tempo, "um anônimo no sentido da individualidade abso-

(22) Raymond Polin - La création des valeurs, 1944. 
luta, e um anônimo no sentido da generalidade absoluta" (23). O homem não pode se eleger continuamente, constituindo-se a partir do nada, nem lhe é dado manter-se suspenso no nada. Por outro lado, a nossa liberdade jamais está só, pois é da sua natureza não se realizar sem cúmplices: o seu poder de perpétuo desvencilhamento funda-se em sua fôrça de participação no mundo. Isto posto, impossível se torna delimitar, na experiência dos valores e da história, qual será "a parte da situação" cultural e social, e qual "a parte da liberdade."

O importante, porém, não é essa determinação de lindes ou de fatôres no jôgo do processo histórico: do ponto de vista ético, o que importa é viver o nosso tempo para compreender os outros tempos. Se, no fundo, não é possível uma resposta teórica ao problema da liberdade, todos nós pressentimos que não podemos querer a nossa liberdade sem sairmos do círculo de nossa singularidade, sem querermos, pura e simplesmente, a liberdade.

18 - Se nas orientações acima recordadas já se encontra quem negue ou duvide da possibilidade de um conhecimento teórico da liberdade ou dos valores, tal agnosticismo alastra-se por todo o campo da ética e da praxis na corrente dos neopositivistas ou de posições afins.

A rigor, aos olhos de um neopositivista configura-se totalmente destituído de sentido o tema que estamos apreciando, especialmente quando se busca uma correlação entre liberdade e valor. No máximo, a matéria poderá ser objeto de verificações de ordem empírica, no plano dos dados da experiência: verificando-se por exemplo, que certos homens agem no pressuposto de serem livres e movidos

(23) M. Merleau Ponty - Phénoménologie de la perception, 1945, pág. 496 e segs. 
por determinados valores, seria possivel indagar, como faz Stevenson, do significado emocional da linguagem ética, ou de sua função descritiva e expressiva (24). Ir além disso seria perder-se em conjeturas destituídas de qualquer certeza ou validade científica.

Sob um outro prisma ainda poderia o assunto merecer atenção, estudando-se a liberdade e o valor em sua conexão semântica ou lógico-linguística, isto é, seu puro valor expressivo, enquanto correspondentes a proposições como estas: "o homem quer, deve, pode, é obrigado a" (will, ought, may, must), relativas a certas classes de fenômenos e a certos comportamentos previsíveis ou não (25).

Estas e outras compreensões do tema não ultrapassam, talvez, o campo descritivo e formal e, muito embora possam contribuir como às vêzes contribuem, para precisar determinados aspectos da ética e da axiologia, deixam em suspenso ou em singelo olvido perguntas fundamentais, verdadeiros pressupostos condicionadores das pesquizas desenvolvidas, e cuja resposta serviria para demonstrar a aparente objetividade das criticas formuladas.

O certo é que o homem, neste intranquilo após-guerra, quanto mais se abisma nos mistérios do cosmos, tanto mais sente a urgente necessidade de dobrar-se sôbre sí mesmo, na intimidade de sua consciência, no sentido do eu profundo, cujo ser é o seu dever ser, onde se entrelaçam liberdade e valor, ser e dever ser, indivíduo e sociedade, existência e transcendência: só então o homem se sente na plenitude de seu ser como pessoa, valor fonte de todos os

(24) Charls L. Stevenson - Ethics and Language, 1944.

(25) RICHARD VON MISEs - Positivism, a study in human Understanding, 1951, pág. 317 e segs. 


\title{
valores, a prescindir do qual não teriam sentido as mais rigorosas e verificáveis conquistas das ciências.
}

\author{
São Paulo, 3 de Setembro de 1957.
}

\begin{abstract}
Summary
Towards the end of Nineteenth Century, the problem of freedom was usually dealt with in the light of a basic distinction between natural and normative laws, the former being understood as strictly causal and universal principles of science. On that ground, the most plausible way to account for freedom itself seemed to consist in interpreting it as a kind of determination of empirical consciousness by normative consciousness.

Today, this somewhat kantian approach to the matter cannot be said to enjoy the same reputation as before, and a good many contemporary philosophical issues are without doubt nothing but problems spring up from its very critique. Already with Kierkegaard and Nietzsche a radical change of perspective took place. The search for freedom turned out to be grounded on men's subjective and creative powers, rather than on something external to him. God and nature were still participating in the process, but the emphasis was mainly laid on human being and action.

Owing also, perhaps, to the break down of strict determinism as a consequence of recent philosophy of science, the analysis of freedom is now more often carried on in ontological than in ethical terms. Thus, while Bergson claims a temporal dimension for any free aspect of the world,Lavelle even maintains that it is freedom's task to create time; and Max Scheler, by criticizing Kant's ethical formalism and subordinating duty to value, characterizes the latter as essentially embodying both free responsibility and obligation.

However, since it fails to do justice to existence or history, every conception of values as absolute and ideal models appears to be unsatisfactory. This is the reason why Heidegger, Sartre, Jaspers, Abbagnano, and other existentialists, instead of trying to find freedom in the revelation of value itself, have preferred to identify it with the ultimate foundation of human life. From such a solution, an obvious impact on any extreme form of rationalistic idealism took rise, so that present spiritualistic and idealistic philosophers like Carlini, Sciacca, and Battaglia tend to locate values in a free, but always open, actualization of possibilities.
\end{abstract}


A full equation of value to freedom seems to be impossible, each term implying the other according to a dialectical relationship of polarity. Only if this fact is clearly recognized, one may hope to understand how what ought to be, or value, can pass into being, or freedom as an unlimited possibility of axiological experiences, without self-nullification.

The basic category through which contemporary naturalism tries to settle the above question is the category of potentiality.

Dewey defines values as natural ends and freedom as an intelligent and dynamic choice of means to their realization. Actual practice, then, when efficient, provides the correlation sought for.

Marxists too, have endeavoured to connect free action with the realization of an ideal in history, but their deterministic conception makes it possible to speak of freedom only as an increase of energies towards removing any obstacle to that effect.

Finally, with logical positivists the whole problem blows over, since it becomes meaningless to ask whether there are links or not between value and freedom. At most one meaningful inquiry is left, on the logico-linguistic or semantical level.

As a general result it should be pointed out that the prevailing tendency shown forth by present analyses of the matter seems to consist in going back to the self, in looking into its depths rather than elsewhere, in scrutinizing human person and consciounsness with a view of discovering there only source of both freedom and value. 